\title{
Modelling sea salt aerosol and its direct and indirect effects on climate
}

\author{
X. Ma, K. von Salzen, and J. Li \\ Canadian Centre for Climate Modelling and Analysis, Environment Canada, University of Victoria, Victoria, British \\ Columbia, Canada \\ Received: 5 September 2007 - Published in Atmos. Chem. Phys. Discuss.: 18 October 2007 \\ Revised: 18 January 2008 - Accepted: 22 January 2008 - Published: 6 March 2008
}

\begin{abstract}
A size-dependent sea salt aerosol parameterization was developed based on the piecewise log-normal approximation (PLA) for aerosol size distributions. Results of this parameterization from simulations with a global climate model produce good agreement with observations at the surface and for vertically-integrated volume size distributions. The global and annual mean of the sea salt burden is $10.1 \mathrm{mg} \mathrm{m}^{-2}$. The direct radiative forcing is calculated to be -1.52 and $-0.60 \mathrm{~W} \mathrm{~m}^{-2}$ for clear sky and all sky, respectively. The first indirect radiative forcing is about twice as large as the direct forcing for all-sky $\left(-1.34 \mathrm{~W} \mathrm{~m}^{-2}\right)$. The results also show that the total indirect forcing of sea salt is $-2.9 \mathrm{~W} \mathrm{~m}^{-2}$ if climatic feedbacks are taken into account. The sensitivity of the forcings to changes in the burdens and sizes of sea salt particles was also investigated based on additional simulations with a different sea salt source function.
\end{abstract}

\section{Introduction}

Natural aerosols are potentially very important for climate. On a global scale, the total mass of natural aerosols is much higher than that of anthropogenically produced types of aerosols, including sulphate, soot and organics. The strongest natural aerosol production rate is that of sea salt, at an estimated 1000-10000 Tg per year (Winter and Chylek, 1997). This is about $30-75 \%$ of the total production rate for all natural aerosols (Blanchard and Woodcock, 1980). Over the ocean, observations (Quinn et al., 1996, 1998, 1999) indicate that sea salt is a particularly important contributor to total aerosol loading. Field campaigns in the eastern Pacific (Covert et al., 1996) show that sea salt accounts for about $90 \%$ of total aerosol mass and $55 \%$ of the sub-micron mass in that region. There is evidence for large variations in the

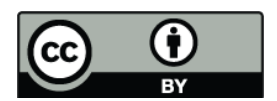

Correspondence to: $\mathrm{X} . \mathrm{Ma}$

(xiaoyan.ma@ec.gc.ca) abundance of the sea salt aerosol in the historical climate record. Ice core studies show two to fivefold change in sea salt fluxes between the last Glacial Maximum and the current climate but these differences are currently poorly understood (Mahowald et al., 2006; Reader and McFarlane, 2003)

Enhanced concentrations of sea salt aerosols at high wind speeds will compete with sulphate aerosol as cloud condensation nuclei. Sea salt may be expected to contribute to the number of cloud droplets on the global scale. However, as was pointed out by O'Dowd et al. (1999a), an increase in cloud droplet number concentration from increased amounts of sea salt aerosol may only occur in remote locations having sufficiently low sulphate concentrations. In that case, increases in sea salt amounts may lead to increased cloud albedo via reduction in the effective cloud droplet size and precipitation efficiency, i.e. via the first and second indirect effects (Twomey, 1974; Albrecht, 1989).

The indirect effect of sea salt is not well quantified yet because the physical processes that determine global aerosol and cloud droplet numbers are poorly understood. For example, Feingold et al. (1999) studied the effects of giant cloud condensation nuclei on drizzle formation in stratocumulus, and found that sea salt may increase precipitation rates at higher $\mathrm{CCN}$ concentrations, opposite to the tendency normally assumed. The effects of aerosols on mixing and evaporation may also be important, which may even lead to positive net radiative forcing (Ackerman et al., 2004).

For realistic simulations of the effects of sea salt aerosol on climate, it is necessary to account for the interactions between sea salt particles and clouds. In this study, the radiative effects of sea salt aerosols are discussed using the prognostic simulations of sea salt aerosol size distributions based on the so-called piecewise log-normal approximation (PLA) method (von Salzen, 2006). The PLA method is briefly described in the following section. Parameterizations based on this method and results from global simulations are described in subsequent sections.

Published by Copernicus Publications on behalf of the European Geosciences Union. 


\section{Piecewise Log-normal Approximation (PLA) method}

Aerosol size distributions are commonly approximated based on the bin approach, also often called "sectional" or "discrete" approach (Gelbard and Seinfeld, 1980; Warren and Seinfeld, 1985; Gelbard, 1990; Jacobson, 1997; Lurmann et al., 1997; Russell and Seinfeld, 1998; Meng et al., 1998; von Salzen and Schlünzen, 1999; Pilinis et al., 2000; Gong et al., 2003; Ma and von Salzen, 2006). According to the bin approach, a range of particle sizes is subdivided into a number of bins, or sections, with discrete values of the size distribution in each bin.

An alternative approach is the so-called modal approach and moment method. According to this approach, aerosol size distributions are approximated using statistical moments with idealized properties (Whitby, 1981; Whitby and McMury, 1997; McGraw, 1997; Ackermann et al., 1998; Wilson et al., 2001; Wright et al., 2001; Yu et al., 2003). Typically, a number of overlapping log-normally distributed modes are assumed to account for different types of aerosols.

von Salzen (2006) introduced a piecewise log-normal approximation (PLA) method in an attempt to exploit the advantages offered by the modal approach (e.g. observed aerosols are often nearly log-normally distributed in parts of the size spectrum) and the bin approach (e.g. flexibility and simplicity). The greater accuracy of the PLA as compared to bin methods has been demonstrated in prognostic simulations with a single column model (von Salzen, 2006).

According to the PLA method, an aerosol number distribution can be approximated by

$n(\varphi)=\sum_{i} n_{i}(\varphi)$

for the dimensionless size parameter $\varphi \equiv \ln \left(R_{p} / R_{0}\right)$, with particle radius $R_{p}$, and reference radius $R_{0}$ (here $1 \mu \mathrm{m}$ ). The following set of functions in Eq. (1) was proposed:

$n_{i}(\varphi)=n_{0, i} \exp \left[-\psi_{i}\left(\varphi-\varphi_{0, i}\right)^{2}\right] H\left(\varphi-\varphi_{i-1 / 2}\right) H\left(\varphi_{i+1 / 2}-\varphi\right)$

where $n_{0, i}, \psi_{i}$, and $\varphi_{0, i}$ are fitting parameters that respectively determine the magnitude, width and the location of the maximum of the distribution. $H(\mathrm{x})$ denotes the Heaviside step function which is used to constrain each log-normal distribution to the particle size range $\varphi_{i-1 / 2}$ to $\varphi_{i+1 / 2}$ for each section $i$. Hence, Eqs. (1) and (2) define a piecewise lognormal approximation (PLA) of the aerosol number distribution. In order to obtain the fitting parameters $n_{0, i}, \psi_{i}$, and $\varphi_{0, i}$ in Eq. (2), it was proposed to prescribe the width $\psi_{i}$ and to calculate the other two parameters from the integrated number $\left(N_{i}\right)$ and mass $\left(M_{i}\right)$ concentrations in each section. These calculations can be made quite efficient in models if they are based on look-up tables (von Salzen, 2006).

Simulations in this study are based on 2 size sections for dry particle radius range from $R=0.05$ to $0.79 \mu \mathrm{m}$ and $R=0.79$ to $12.5 \mu \mathrm{m}$. Therefore, 4 additional tracers ( 2 for number and 2 for mass) were introduced in the model. Sensitivity tests with larger numbers of sections did not reveal any significant advantages so it was decided that this approach was sufficient.

\section{Model description}

In the current study, a developmental version of the $\mathrm{CC}$ Cma 4th generation atmospheric general circulation model (AGCM4) (von Salzen et al., 2007 ${ }^{1}$; von Salzen et al. (2005)) is used to study direct and indirect effects of sea salt. The spectral resolution used in AGCM4 for this study corresponds to a spherical harmonic expansion triangularly truncated at total wave number 47 . The model domain extends from the surface to the stratosphere. There are 35 layers in the vertical, with a grid spacing of approximately $100 \mathrm{~m}$ near the surface that monotonically increases with height.

\subsection{Sea salt aerosol production}

Sea salt aerosol particles are formed predominantly by the action of the wind on the ocean. The wind stress on the the ocean surface forms waves, some of which break and entrain air to various depths. The bubbles rise to the surface, creating whitecaps, and burst, injecting seawater drops into the atmosphere.

Most of the earlier studies (e.g. Gong et al., 1997; Grini et al., 2002; Pryor and Sorensen, 2000) used the parameterization that was developed by Monahan et al. (1986). This parameterization is based on laboratory measurements and is generally limited to particles with radius bigger than $0.8 \mu \mathrm{m}$ at a relative humidity of $80 \%$. Futhermore, some studies (Smith et al., 1993; Gong et al., 1997; Pryor and Sorensen, 2000) pointed out that the fluxes given by Monahan et al. (1986) were too big for the spume droplet regime, in which the droplets are torn directly from the wave crests at high wind speed.

Based on field measurements at different sites, Lewis and Schwartz (2004) plotted size distributions of sea salt aerosol at various wind speeds. They found that the shape of the average number size distribution for all measurements is roughly independent of wind speed, i.e.

$n\left(r_{80}\right)=\frac{d N}{d \log _{10} r_{80}}=0.07\left(U_{10}\right)^{2} \exp \left\{-\frac{1}{2}\left[\frac{\ln \left(r_{80} / 0.3\right)}{\ln 2.8}\right]^{2}\right\}$

Where $N$ is the number concentration in particles $/ \mathrm{cm}^{3}, r_{80}$ is the particle radius in $\mu \mathrm{m}$ at $80 \%$ humidity, and $U_{10}$ is the wind speed at $10 \mathrm{~m}$ height in $\mathrm{m} \mathrm{s}^{-1}$. This expression fits the

\footnotetext{
${ }^{1}$ von Salzen, K., Lazare, M., Li, J., McFarlane, N., et al.: The climate and its sensitivity in simulations with the canadian centre for climate modelling and analysis fourth generation Atmospheric Global Climate Model (CCCma AGCM4). Part 1: Model description and climatology, in preparation, 2007.
} 
bulk of the data fairly well. However, the associated uncertainty is a factor of 3 for aerosol number, area and mass. The parameterization is limited to the particle diameters greater than $0.1 \mu \mathrm{m}$ as there were only few observations available for smaller particles and concentrations are expected to be generally small according to Lewis and Schwartz (2004). For similar reasons, only particle diameters less than $25 \mu \mathrm{m}$ are considered.

The sea salt concentration in the first layer in the AGCM over ocean is specified as a function of simulated wind speed at each individual model time step. Consequently, simulated sea salt size distributions in that layer are exactly identical to mean observational results according to Lewis and Schwartz (2004). Concentrations in the first model layer over the ocean are used as boundary conditions in calculations for processes that occur above this layer and over land. Similar to other prognostic tracers in the AGCM, sea salt aerosol is affected by transport (i.e. advection, convection, turbulent mixing) and wet deposition.

The application of a sea salt source in terms of concentrations in this study generally requires less substantial approximations in contrast to the more frequently used specification of sea salt surface fluxes in GCMs. Parameterizations of surface fluxes are usually based on observed size distributions and assumptions about the transfer of the particles from the surface to the observation level under equilibrium conditions. For application of flux parameterizations in models, parameterizations of boundary layer mixing and deposition processes introduce additional uncertainties for simulated sea salt size distributions. In contrast, the method used here provides a much more direct connection between simulated and observed sea salt size distributions and associated uncertainties. However, a potential disadvantage of the method is that mean sea salt size distributions are assumed to be in equilibrium with surface winds in individual grid cells. This can be expected to be a good approximation for AGCMs with time steps on the order of tens of minutes and grid sizes on the order of hundreds of kilometres owing to rapid turnover of sea salt particles in the planetary boundary layer over the ocean (Lewis and Schwartz, 2004). However, it may not be a good approximation for much smaller time steps and grid sizes.

Most of the results in this paper are based on the approach above. However, in order to address uncertainties that are associated with parameterizations of the sea salt source function, additional results for a parameterization of the sea salt surface flux which was proposed by Clarke et al. (2006) will be presented in Sect. 6.3.

\subsection{Particle growth}

Sea salt particles are highly water soluble and so as the relative humidity increases, the size of the particles will also increase. The equilibrium condition for a solution droplet in moist air is given by the Köhler equation,

$\mathrm{RH}=a_{w} \exp \left(\frac{A^{\prime}}{f_{r}}\right)$

where $f_{r}=r / r_{d}$ is the ratio of the actual particle radius over the dry particle radius $r_{d}$ (assuming a sphere). The exponential in this equation accounts for effect of particle curvature on the relative humidity, with $A^{\prime}$ given by

$A^{\prime}=\frac{2 \sigma}{\rho_{w} R_{w} T r_{d}}$

where $\sigma$ is the surface tension between the droplet and air, $\rho_{w}$ is the density of water, $R_{w}$ is the gas constant for water vapour, $T$ is the temperature. Since sea salt particles considered in this study are larger than $0.1 \mu \mathrm{m}$, the Kelvin effect is expected to be very small.

The exponential form for the water activity is

$a_{w}=\exp \left(-\phi v \frac{M_{w}}{M_{s}} \frac{m_{s}}{m_{w}}\right)$

where $\phi$ is the osmotic coefficient for an aqueous solution of sea salt, that is obtained from the measurements (Tang et al., 1997). $v$ is the volume of the droplet, $M_{w}$ is the molecular weight of water, $M_{S}$ is the molecular weight of sea salt. $m_{s}$ and $m_{w}$ denote the masses of sea salt, water respectively. Using Eqs. (5) and (6), the Köhler equation can be written:

$\ln \mathrm{RH}=\frac{A^{\prime}}{f_{r}}-\frac{B}{f_{r}^{3}-1}$

where

$B=\phi v \frac{M_{w}}{M_{s}} \frac{\rho_{p d}}{\rho_{w}}$

$\rho_{p d}$ is the dry density of the aerosol. $\phi$ has been obtained as a function of $\mathrm{a}_{w}$ based on a fit to laboratory results. An iterative procedure is used to obtain $f_{r}$ from Eq. (7) (Gong et al., 2003; Ma and von Salzen, 2006).

\subsection{Gravitational settling}

The terminal settling velocity of a spherical aerosol particle is given by

$v_{t}=\frac{2}{9} \frac{r^{2} \rho_{p w} g C_{c}}{\mu}$

with the radius $\mathrm{r}$, density of the wet aerosol $\rho_{p w}$, gravitational acceleration $\mathrm{g}$, slip correction factor $\mathrm{C}_{c}$ and viscosity of air $\mu$ (Seinfeld and Pandis, 1998). The slip correction factor is only for smaller particles, so it is unimportant for sea salt particles and can be assumed unity.

For application of the PLA method, effective terminal settling velocity for particle number $\left(v_{t n, i}\right)$ and mass $\left(v_{t m, i}\right)$ in each section $i$ were calculated by integrating over the sections, i.e.

$v_{t n, i}=\frac{1}{N_{i}} \int_{\varphi_{w, i-1 / 2}}^{\varphi_{w, i+1 / 2}} v_{t} n\left(\varphi-\triangle \varphi_{w, i}\right) d \varphi$ 

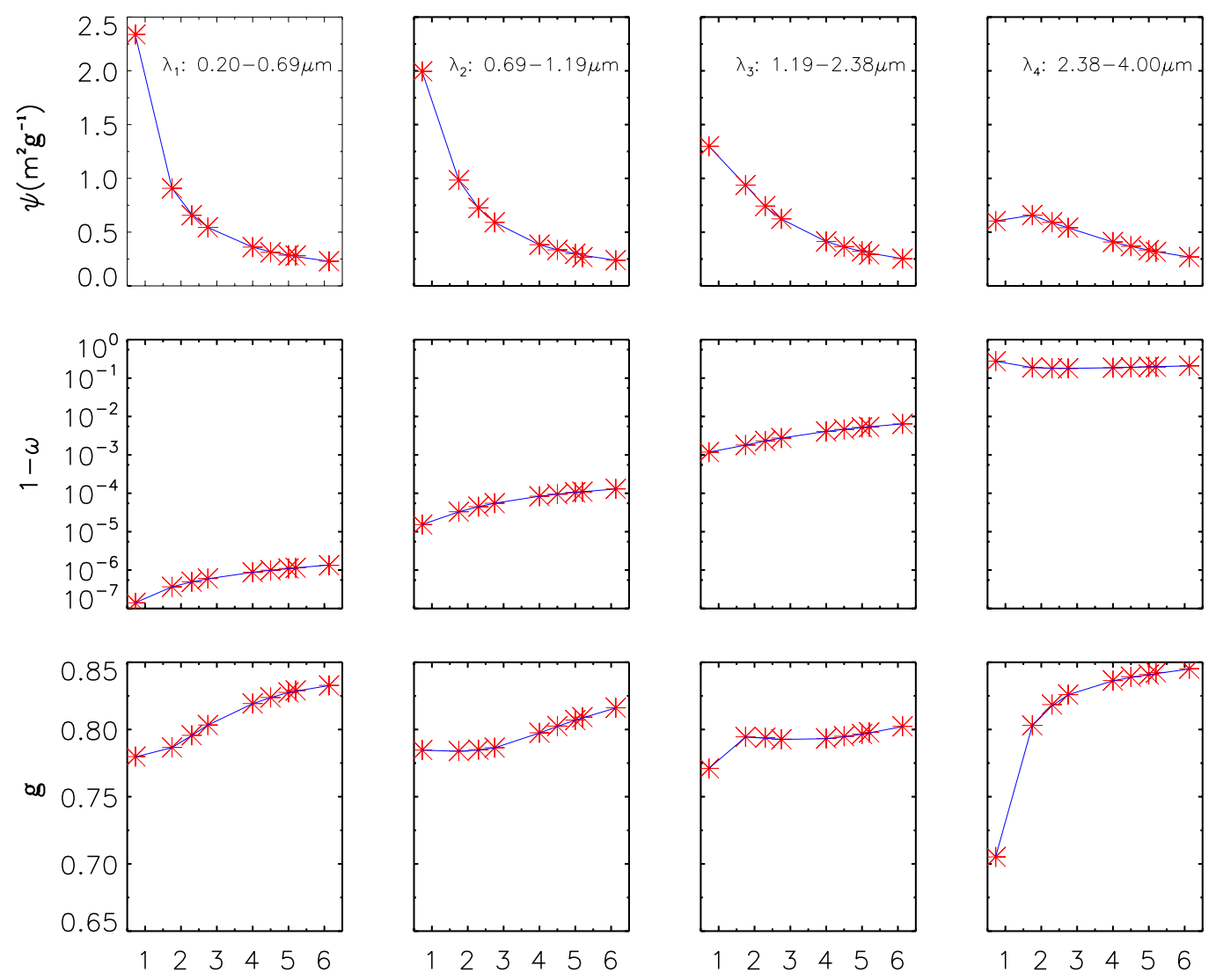

Effective Radius $(\mu \mathrm{m})$

Fig. 1. Comparisons of specific extinction coefficient, single scattering albedo, and asymmetry factor as functions of radius from Mie calculations (solid lines) and the parameterization (dashed lines). This figure is for all 6 radii plus $2.3,4.5$ and $5.2 \mu \mathrm{m}$ at $80 \%$ relative humidity.

$v_{t m, i}=\frac{1}{M_{i}} \frac{4 \pi}{3} \rho_{p w, i} R_{0}^{3} \int_{\varphi_{w, i-1 / 2}}^{\varphi_{w, i+1 / 2}} v_{t} e^{3 \varphi} n\left(\varphi-\triangle \varphi_{w, i}\right) d \varphi$

with $\varphi_{w, i \pm 1 / 2}=\varphi_{i \pm 1 / 2}+\triangle \varphi_{w, i}$ and $\mathrm{R}_{0}=10^{-6} \mathrm{~m}$. Here, $\triangle \varphi_{w, i}=\ln f_{r, i}$ depends on relative humidity (Eq. 4).

Depending on the particle size and surface condition (ocean or land), dry deposition velocities are assumed as different constants.

\subsection{Wet deposition}

The in-cloud removal of particles is parameterized according to

$$
\frac{d C}{d t}=-\frac{a C}{\tau}
$$

Here $C$ is the in-cloud aerosol concentration, $a$ is the cloud fraction. $\tau=\mathrm{LWC} /\left(Q_{\text {aut }}+Q_{\text {acc }}\right)$, LWC is the cloud liquid water content, $Q_{\text {aut }}$ is the rate of autoconversion of cloud liquid water, and $Q_{\text {acc }}$ is the rate of accretion of cloud liquid water by rain (Croft et al., 2005).
Below-cloud scavenging is parameterized according to Berge (1993)

$$
\frac{d C}{d t}=-B m_{p} E_{m}
$$

where $B=5.2 \mathrm{~m}^{3} \mathrm{~kg}^{-1} \mathrm{~s}^{-1}, m_{p}$ is the precipitation mass $\left(\mathrm{kg} \mathrm{m}^{-3}\right)$ and $E_{m}$ is a mean collection efficiency. Here we assume $E_{m}=0.1$.

For wet deposition in convective clouds, effects of entrainment and detrainment on the balances of the tracers are considered for deep convective and shallow convective clouds, respectively (Ma and von Salzen, 2006).

\subsection{New parameterization for sea salt optical properties}

Currently, the optical calculations in GCMs are based on the assumption that the aerosol particle number is log-normally distributed for a single distribution with constant properties. Although this assumption is convenient in GCM calculations, this approximation may lead to substantial biases. 

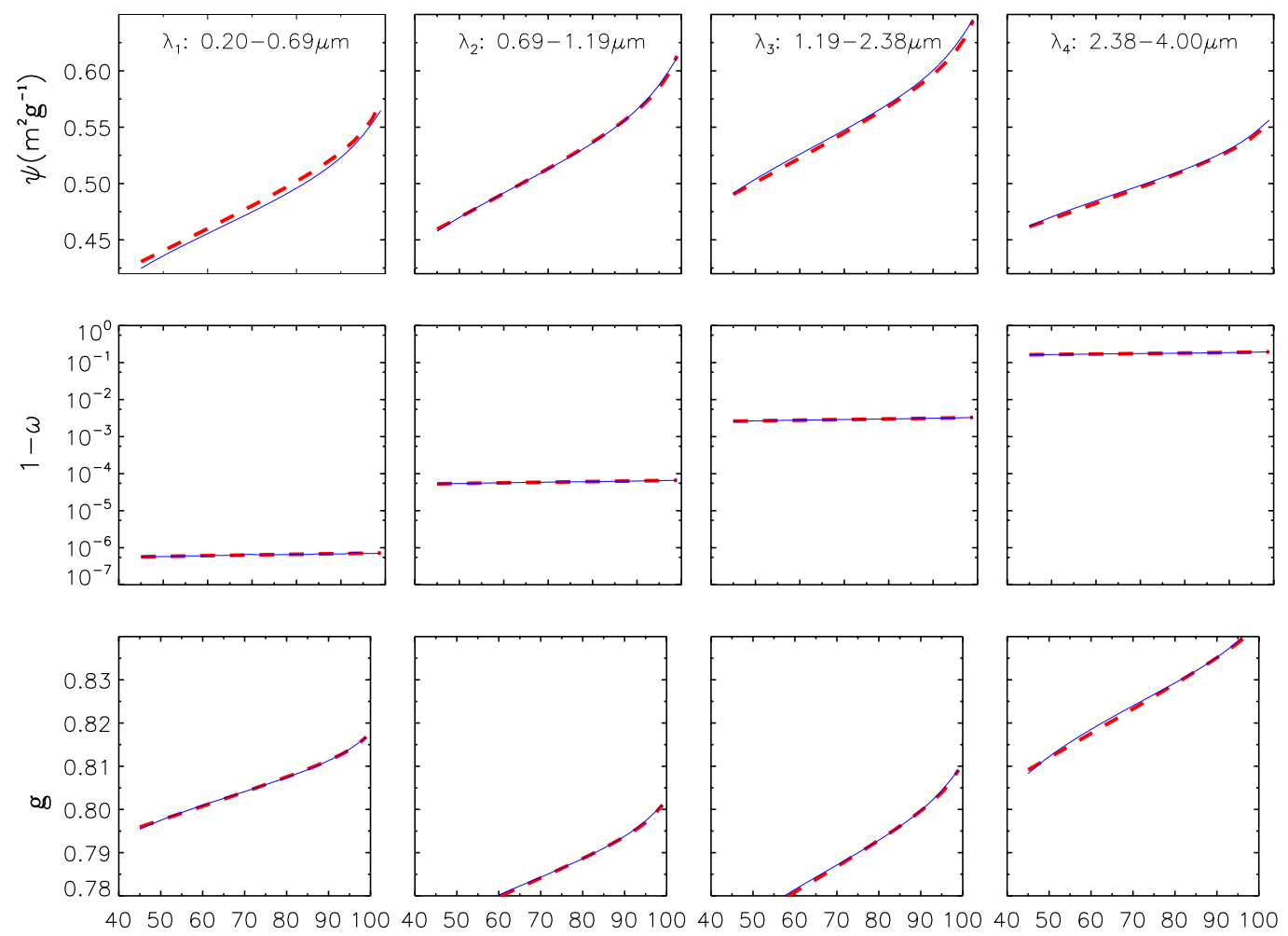

Relative Humidity (\%)

Fig. 2. Comparisons of specific extinction coefficient, single scattering albedo, and asymmetry factor as functions of relative humidity from Mie calculations (solid lines) and the parameterization (dashed lines). This figure is for $r_{e}=3.0 \mu \mathrm{m}$ and $v_{e}=0.65$.

In this study, on-line simulated aerosol size distribution are utilized for calculations of optical properties, i.e. specific extinction coefficient, single scattering albedo, and asymmetry factor of sea salt. Mixing with other particles is not taken into account.

As sea salt aerosol particles are hygroscopic, the sea salt size distribution will vary with relative humidity. The new parameterization was developed to directly account for the optical properties of wet particles ( $\mathrm{Li}$ et al., $2007^{2}$ ). In order to minimize the computational burden, 6 effective radii $(0.73,1.75,2.75,4.00,5.00$ and $6.13 \mu \mathrm{m})$ and 2 effective variances $(0.65$ and 0.85$)$ were chosen for offline Mie calculations. In the AGCM, the Lagrangian method is employed to interpolate between tabulated results from the Mie calculations for different aerosol size distributions. The accuracy of optical properties from this parameterization were compared to exact Mie calculations to test the approach (Fig. 1). This comparison gives evidence that the parameterization gives accurate results for the optical properties of sea salt aerosols. The relative errors for the 6 radii are less than $1 \%$. For further comparison, the optical properties are calculated for ad-

\footnotetext{
${ }^{2} \mathrm{Li}$, J., Ma, X., von Salzen, K., and Dobbie, S.: Parameterization of sea salt optical properties and physics of related radiative forcing, J. Atmos. Sci., submitted, 2007.
}

ditional radii including $2.3,4.5$, and $5.2 \mu \mathrm{m}$ and then compared to the results from the parameterization. These results are also shown in Fig. 1. The maximum of the relative error for these results is less than 6\%. As expected, the scattering efficiency decreases with increasing particle size. Figure 2 shows the change in optical properties with relative humidity for $r_{e}=3.0 \mu \mathrm{m}$ and $v_{e}=0.65$. It is shown that the parameterized optical properties for the 4 bands are all very close to the Mie calculations. For both solutions, the particle extinction increases with the relative humidity.

For application of the approach in combination with the PLA method, the effective radius and variance of the sea salt size distribution is determined in each grid cell by integrating over the predicted size distribution.

\section{Direct and indirect aerosol radiative forcing of cli- mate}

Sea salt aerosol directly scatters solar radiation back to space and thereby causes surface cooling, which is commonly referred to as the direct effect. In addition to direct radiative effects, water-soluble aerosols, such as sea salt aerosol, affect climate via indirect effects. The first indirect effect refers to the radiative impact of a reduction in cloud droplet effective 

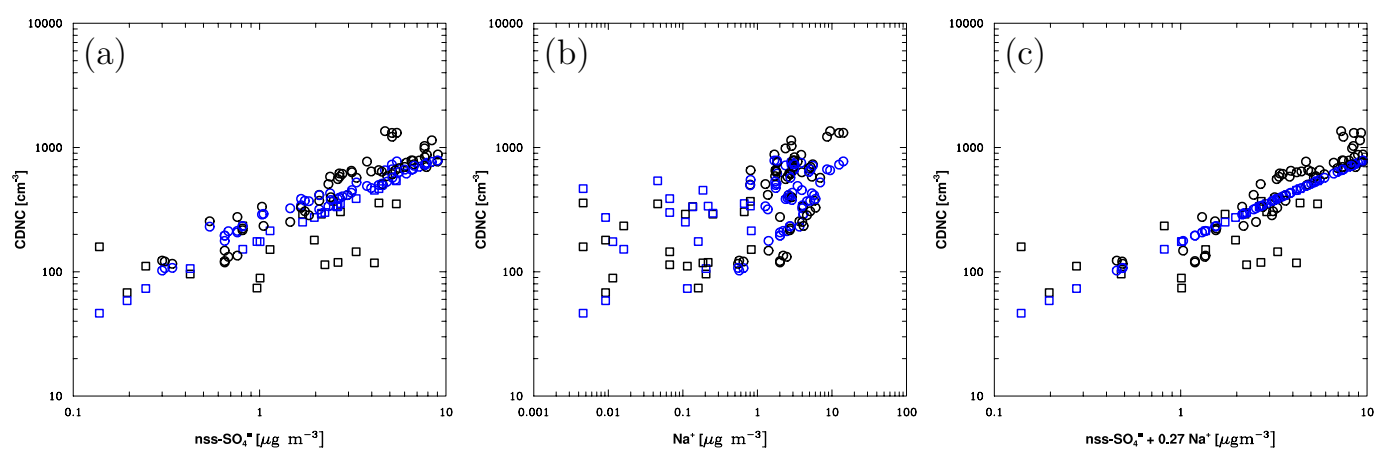

Fig. 3. Parameterized (blue) compared to observed (black) cloud number concentrations as function of non-sea salt sulphate (a), sodium (b), and non-sea salt sulphate plus sodium (c) concentrations. Circles refer to observations by Borys et al. (1998), squares to observations by Leaitch et al. (1996).

radius that is associated with increased cloud droplet number concentration for constant cloud water content. A decrease in effective radius results in an increase in cloud optical depth and cloud albedo (Twomey, 1974). The second indirect effect refers to the radiative impact of a decrease in precipitation efficiency that is associated with increased cloud droplet number concentration (Albrecht, 1989). A decrease in precipitation efficiency may result in an increase in cloud liquid water path and average cloud fraction and may thereby lead to additional increases in cloud albedo.

The cloud droplet number concentration (CDNC) depends on the distribution of cloud condensation nuclei $(\mathrm{CCN})$, which is a fraction of the total aerosol number concentration. Aerosol activation, i.e. cloud droplet formation by heterogeneous nucleation in which water vapour condenses on $\mathrm{CCN}$, has been examined in various numerical and/or experimental studies (Ghan et al., 1997; Abdul-Razzak, et al., 1998; Abdul-Razzak and Ghan, 2000, 2002; Nenes and Seinfeld, 2003; Stratman et al., 2004).

Currently, the treatment of CDNC is relatively simple in most GCMs because subgrid variations in vertical velocity, maximum supersaturation, and availability of $\mathrm{CCN}$ are difficult to parameterize in GCMs. Although there are studies using a physically-based activation in GCMs (Penner et al., 2006), empirical relationships between CDNC and sulfate aerosol concentration based on measurements of aerosol, CCN and CDNC are widely used in operational global climate models (Jones and Slingo, 1994; Boucher and Lohmann, 1995; Lowenthal et al., 2004).

Earlier studies often assumed that sulphate is the only significant source of $\mathrm{CCN}$. However, observations show that sea salt aerosol is a dominant contributor to $\mathrm{CCN}$ concentrations in some regions of the remote marine atmosphere where concentrations of other types of the aerosol, such as sulphate aerosols, are low (Quinn et al., 1998, 2000).

In this study the usual empirical approach is extended to sea salt aerosol. Measurements for the North Atlantic from Leaitch et al. (1996) and Borys et al. (1998) were used to derive the following relationship between CDNC (per cubic meter) and sulphate and sea salt mass concentrations (in $\mathrm{mg} \mathrm{m}^{-3}$ ):

$$
\log _{10}(\mathrm{CDNC})=2.24+0.67 \log _{10}\left(\mathrm{SO}_{4}^{2-}+0.27 \mathrm{Na}^{+}\right)
$$

The coefficients in Eq. (14) were estimated using least squares fitting for $\log _{10}$ (CDNC). The functional relationship in this equation is based on the assumption that the net effect of sea salt and sulphate aerosol on CDNC can be characterized based on a linear combination of sulphate and sea salt concentrations (i.e., last term in Eq. 14). Results shown in Fig. 3 give evidence that the available observations can be well represented by this approach. Unfortunately, it was not possible to test the parameterization for conditions other than those for the North Atlantic owing to a lack of sufficient observations. Further, similar to other parameterizations, Eq. (14) does not include contributions from organic aerosol which may also affect the results, particularly near and downwind of continental source regions.

According to O'Dowd et al. (1999a), sea salt aerosol tends to reduce the number of activated sulphate aerosol particles under highly polluted conditions owing to reductions in cloud supersaturation. The parameterization proposed here does not account for this effect. However, O'Dowd et al. (1999b) proposed a parameterization of CDNC as a function of a linear combination of number concentrations of sulphate and sea salt particles for global models. Their parameterization produced good agreement with results of detailed microphysics calculations, lending support to the approach used here. It should be noted that sulphate aerosol number concentrations are not available from AGCM4 so that their parameterization was not used in the current study.

For application of the parameterization in the AGCM, the bulk sulphur cycle in the AGCM is used, which produces concentrations for externally mixed sulphate aerosol (von Salzen et al., 2005; Lohmann et al., 1999). Processes that are accounted for in the sulphur cycle include clear-sky and in-cloud production of sulphate, wet and dry deposition. 
(a)

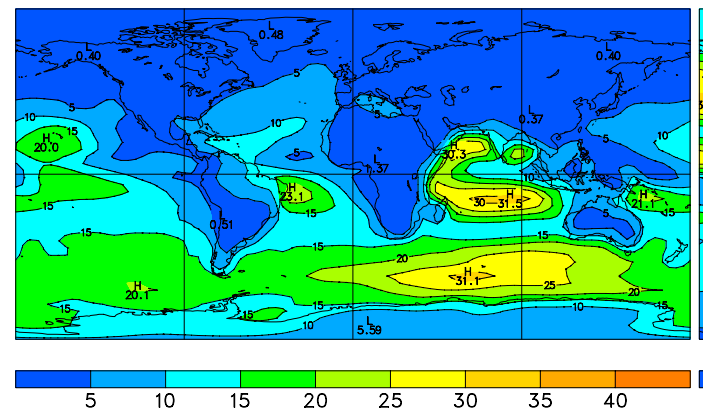

(b)

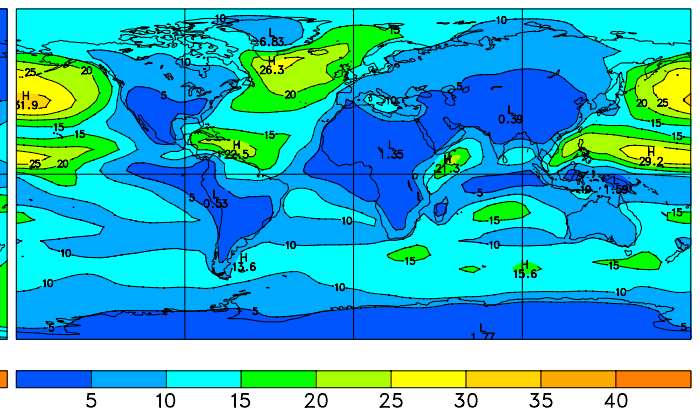

Fig. 4. Simulated sea salt burden (in $\mathrm{mg} / \mathrm{m}^{2}$ ) for JJA (a) and DJF (b).

Observations and results from detailed microphysical models give evidence that CDNCs strongly depend upon the aerosol near the cloud. Consequently, the CDNC can be parameterized in terms of large-scale aerosol concentrations to a first approximation. Hence, grid-cell mean concentrations are used in the parameterization of CDNC for each completely or partly cloudy AGCM grid cell and at each time step. In the future, parameterizations of aerosol activation will be used in AGCM4 in combination with other microphysics parameterizations for a more rigorous treatment of CDNC.

For the representation of the second indirect effect, aerosol effects on autoconversion are considered for layer clouds in AGCM4. The parameterization of the autoconversion rate that was proposed by Khairoutdinov and Kogan (2000) is used, which explicitly depends on CDNC. The layer cloud microphysical scheme is based on a scheme that was developed by Lohmann and Roeckner (1996), which is based on prognostic equations for the mass mixing ratios of water vapour, cloud liquid water, and cloud ice (von Salzen et al., 2005).

\section{Results}

The sea surface temperature (SST) and sea ice in the simulation are from the second phase of the Atmospheric Model Intercomparison Project (AMIP) for the period January 1956 through December 2000 (von Salzen et al., 2007 ${ }^{1}$ ). In the following, mean results for a 10 year simulation are discussed, after an initialization period of 11 months.

\subsection{Sea salt concentration and burden}

The global simulated distribution of the sea salt burden is shown in Fig. 4. The distribution and seasonal variation is largely determined by the spatial distribution of the wind speed above the surface of the ocean.

The global and annual mean burden of sea salt is $10.1 \mathrm{mg} \mathrm{m}^{-2}$ in this study. Results from previous studies listed in Table 1 show that the result of this study is within the range of previous studies. The results agree particularly well
Table 1. Global and annual mean burden of sea salt. Unit: $\mathrm{mg} \mathrm{m}^{-2}$.

\begin{tabular}{lll}
\hline & source & reference \\
\hline 10.1 & model & this study \\
11.0 & satellite & Takemura et al. (2000) \\
14.8 & AeroCom & Textor et al. (2006) \\
13.6 & model & Liao et al. (2004) \\
12.0 & model & Grini et al. (2002) \\
15.0 & compiled & Koepke et al. (1997) \\
22.4 & model & Tegen et al. (1997) \\
23.9 & model & Mahowald et al. (2006) \\
7.5 (low case) & model & Haywood et al. (1999) \\
36.8 (high case) & & \\
\hline
\end{tabular}

with the satellite-based estimate by Takemura et al. (2000). However, most models tend to produce somewhat higher burdens.

\subsection{Comparison with observations}

Figure 5 shows the sites that were used in the following comparison with observed sea salt concentrations (J. M. Prospero and D. L. Savoie, personal communication). Results of the comparison for seasonal mean surface concentrations are shown in Fig. 6. The simulated sea salt concentrations agree well with the observations for most sites in the North Atlantic and North Pacific. Large differences exist for the sites in tropical areas. In particular, the model tends to substantially underestimate concentrations in the tropics. The model also tends to over-predict Antarctic concentrations.

Time series of monthly mean surface concentrations at all locations are shown in Fig. 7. Overall, the model captures the observed seasonal variations, i.e. maximum wintertime concentrations in the Northern Hemisphere, and weaker seasonal variations in the Southern Hemisphere. In particular, the seasonal variations are well reproduced for the sites 23 , 25, 26, 27, 28 in the North Atlantic. The model results from this study agree well with simulated sea salt concentrations by Liao et al. (2004) in which a different numerical 


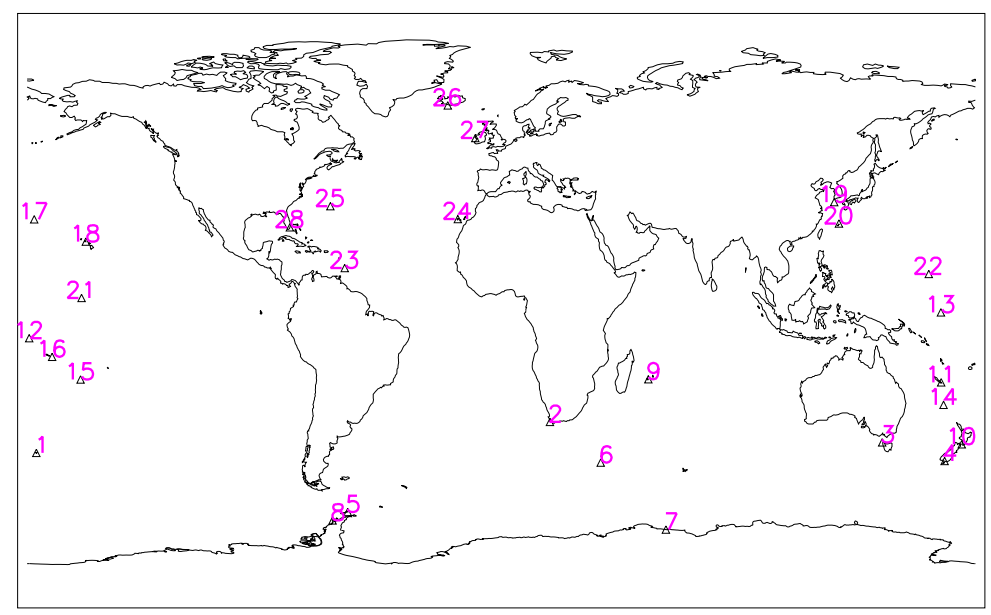

Fig. 5. Locations of sites with observational data used for comparisons.
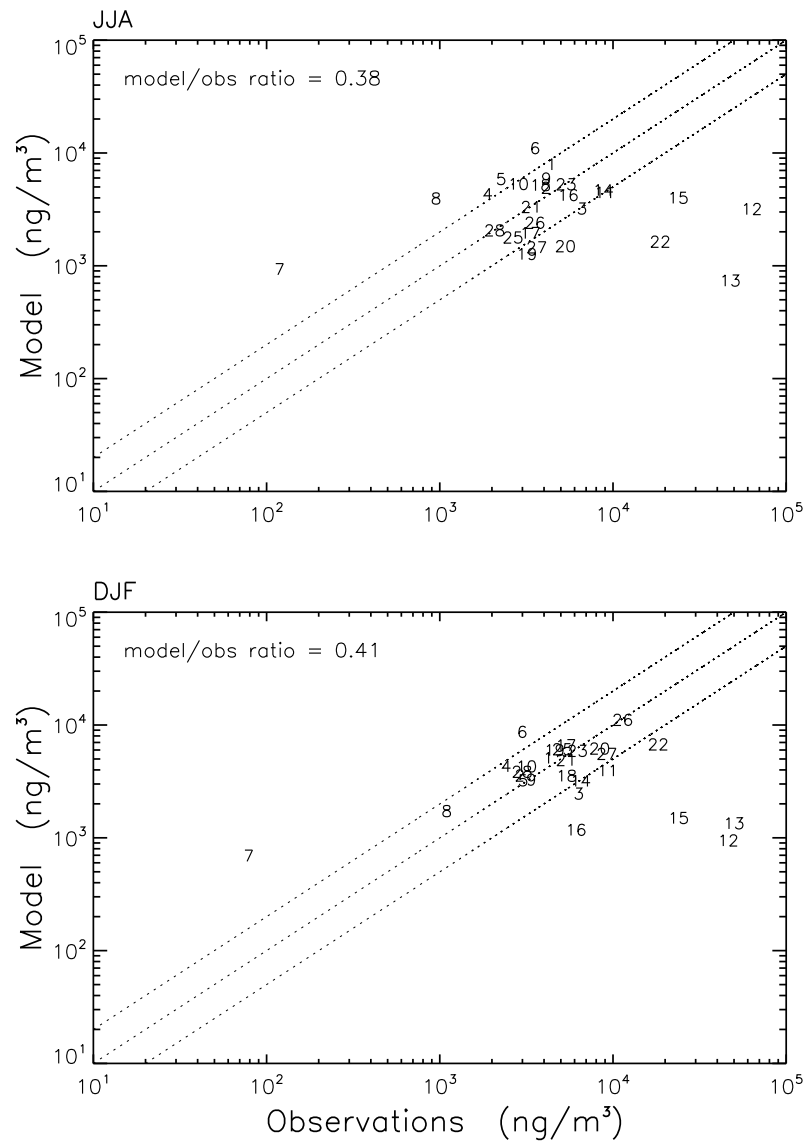

Fig. 6. Comparison between simulated and observed surface mass concentration of sea salt. The dash lines indicate 2:1, 1:1, and 1:2 ratios. Modelled versus observed ratios and correlation coefficients are indicated in each plot. approach (bin approach) and sea salt source parameterization was used to predict aerosol size distributions. However, the model generally produces too low concentrations for tropical Pacific sites $(12,13,22)$. A comparison between simulated wind speed and ECMWF ERA-40 reanalysis results does not provide evidence for any systematic underestimates in wind speeds in the simulation which might lead to insufficiently high concentrations according to Eq. (3). It therefore seems possible that the parameterization of sea salt production (Lewis and Schwartz, 2004) may not be representative of tropical conditions. Wind speed based formulations of aerosol concentrations and sources, such as Eq. (3), are implicitly based on the assumption that the local sea state is directly related to the local wind speed. However, satellite observations of whitecap coverage give evidence that the local sea state is determined by factors other than just wind speed (Anguelova and Webster, 2006). In particular, the observed whitecap coverage in tropics is higher than would be expected based on the wind speed. It is also noted that spurious concentration trends occur for some tropical sites according the observations, i.e. discontinuous changes between January and December $(12,13)$. Furthermore, the model results are for large-scale averages of surface concentrations while observations provide concentrations at specific locations which may not necessarily be representative of mean conditions, e.g. if observations are performed near the surf zone. However, an analysis of the differences between model results and surface observations is beyond the scope of this study.

The AERONET (Aerosol Robotic Network) (Holben, 1998) dataset is used for further comparisons. AERONET provides column integrated aerosol size distribution from sun-photometer measurements in various geographical locations (see Fig. 6 of Ma and von Salzen, 2006). Similar to AERONET, only simulation results for clear sky conditions and during daytime are used in the comparison. For 

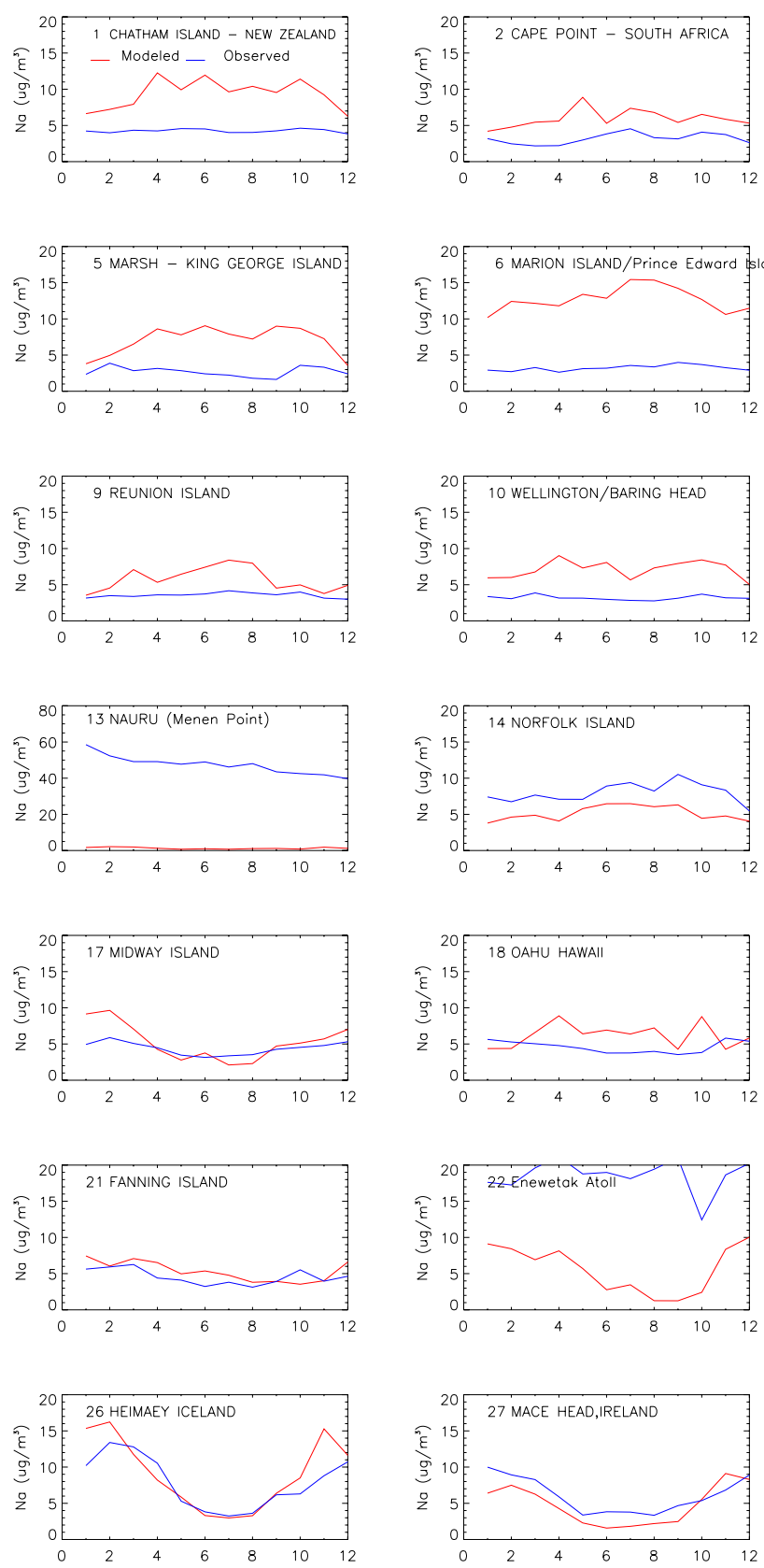
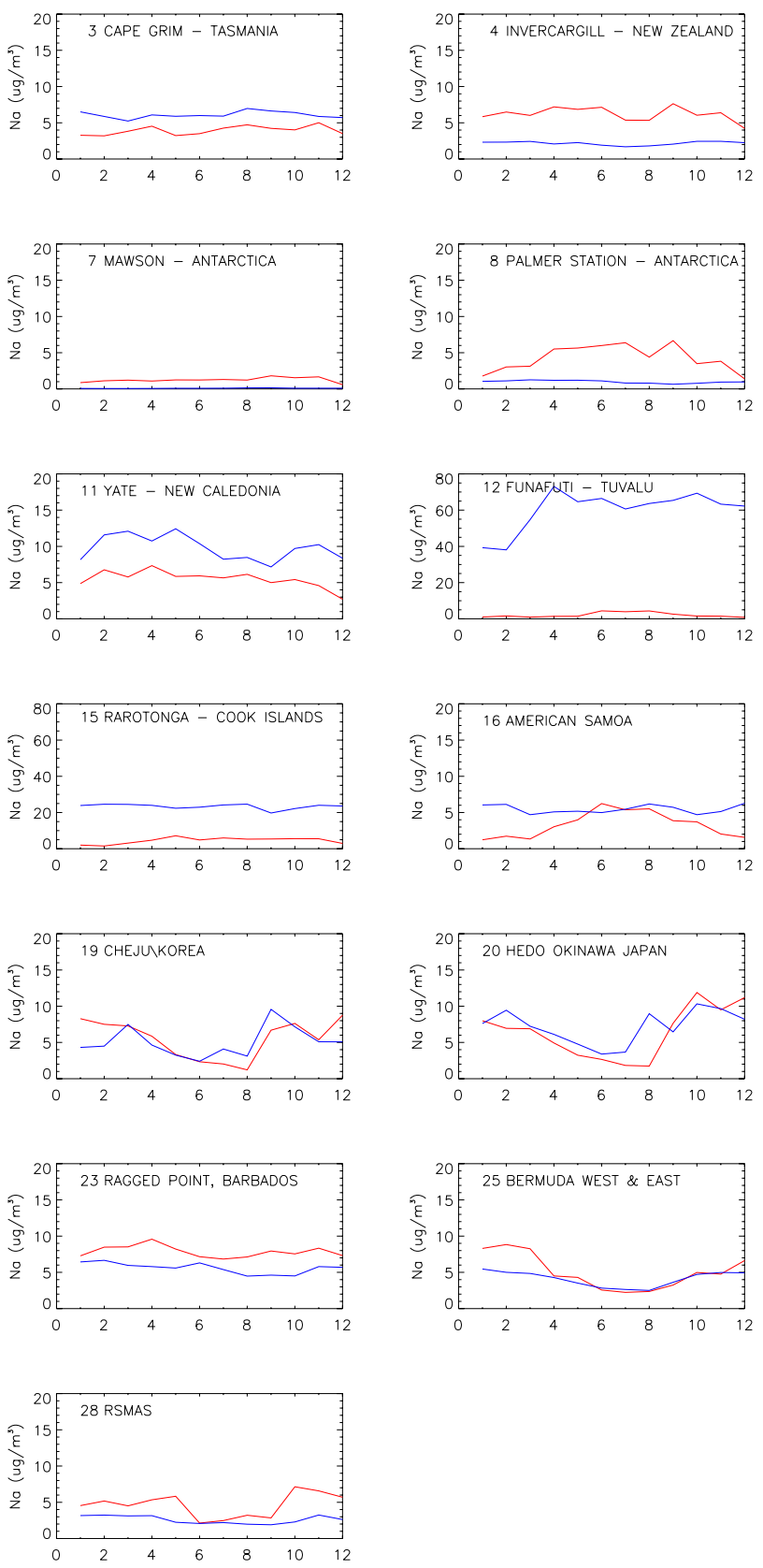

Fig. 7. Annual cycle of surface sea salt concentrations at the various observational sites listed in Fig. 5.

the comparisons, the simulated sea salt size distributions are interpolated on-line in the model to the same size bins that AERONET provides.

Figure 8 a shows the simulated and observed seasonally averaged aerosol volume size distributions for the AERONET data. The simulated aerosol volume due to sea salt is generally lower than observations for all land and ocean AERONET sites, which is consistent with the fact that AERONET measures concentrations from all aerosols, including mineral dust, which dominates coarse aerosol parti- cle concentrations over land but is not included in the model. The simulated aerosol volume is more similar to the observations for the ocean sites (Fig. 8b), indicating that the model can reasonably well reproduce the observed size distributions for the coarse mode for most locations over the ocean, where sea salt is believed to dominate.

Similarly, the far greater concentrations of fine aerosols in the observations compared to the model results is expected, as these are associated with other aerosol types, specifically, sulphate and organic carbon. These are not included in the 
(a)

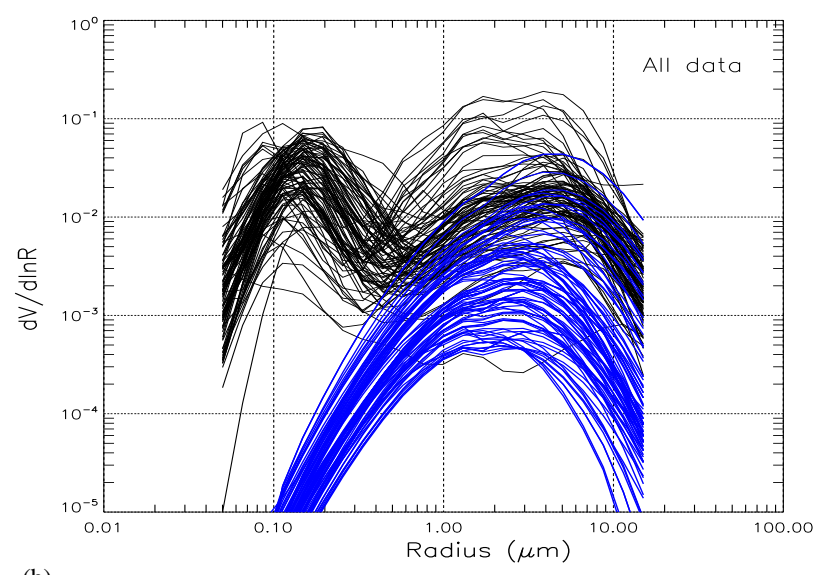

(b)

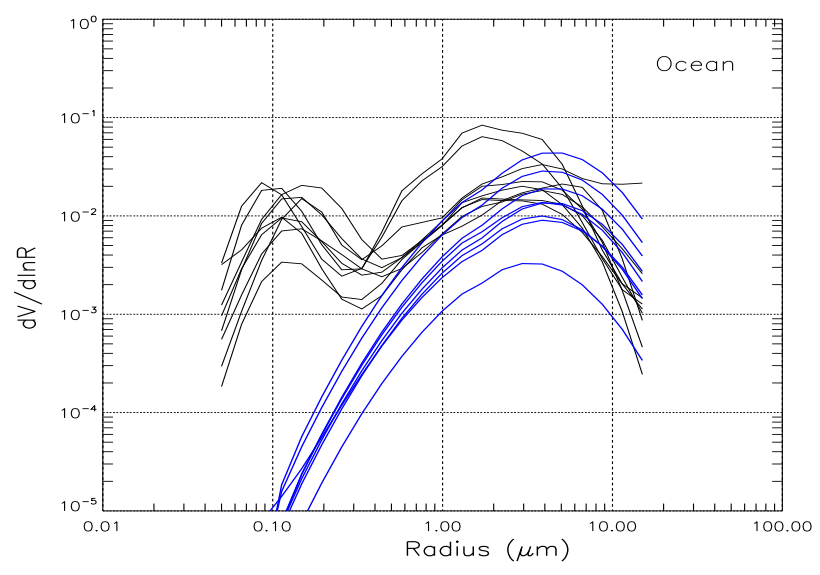

Fig. 8. Comparison between simulated (blue) and observed (black) vertically integrated volume size distributions. Observations are for multi-year averaged results from AERONET. Results for all AERONET site are shown in (a) including land sites. (b) only shows results for the ocean sites.

comparison since the size distributions are not simulated for these species.

\section{Radiative forcing}

\subsection{Direct radiative forcing}

The aerosol direct radiative forcing (DRF) is defined as the difference between net radiative fluxes at the top of atmosphere (TOA) in the absence and presence of sea salt in the model. Figure 9 shows seasonal mean global distributions of sea salt forcing for clear sky columns in the simulations for June-August (JJA) and December-February (DJF). The global mean clear-sky DRF is $-1.34 \mathrm{~W} \mathrm{~m}^{-2}$ for JJA and $-1.54 \mathrm{~W} \mathrm{~m}^{-2}$ for DJF. It is evident that the distributions of forcing and seasonal variation coincide with those for sea salt concentrations (Fig. 4). The DRF for the Southern Hemi- sphere shows only little seasonal variation. The maximum forcings are located in the midlatitude Southern Hemisphere. Secondary maxima occur over the North Atlantic and North Pacific for DJF. In contrast to the model results, satellite observations based on MODIS radiance (Loeb and ManaloSmith, 2005) do not give any evidence for a strong DRF near $50-60^{\circ} \mathrm{S}$ in JJA. However, the satellite observations show strong the DRF for DJF in this area, similar to the model results.

Figure 10 show the DRF for all-sky conditions, i.e. clouds are included. The all-sky DRF is substantially smaller than the clear-sky DRF (Fig. 9). The global mean all-sky DRF is -0.53 and $-0.64 \mathrm{~W} \mathrm{~m}^{-2}$ in JJA and DJF, respectively. The differences are particularly large at midlatitudes as the cloud cover in these regions is very high. In the less cloudy subtropical regions around $20^{\circ}$, the impact of clouds is smaller, therefore the strongest radiative forcing occurs in these regions. Clouds at midlatitudes therefore strongly reduce the direct radiative impact of sea salt both by wet deposition and scattering of sunlight.

Unlike the shortwave (SW) radiative forcing, the global mean of longwave (LW) forcing is positive, but the value is much lower than $\mathrm{SW}$. The $\mathrm{LW}$ radiative forcing is 0.03 (JJA) and $0.03 \mathrm{~W} \mathrm{~m}^{-2}$ (DJF) in clear sky, and 0.14 (JJA) and $0.16 \mathrm{~W} \mathrm{~m}^{-2}$ (DJF) in all-sky conditions. One analysis based on radiative transfer ( $\mathrm{Li}$ et al., $2007^{2}$ ) indicates that the $\mathrm{LW}$ forcing in the troposphere is generally positive due to a reduction of temperature with height.

A comparison of direct forcings in various studies is listed in Table 2. The global mean forcing in this study is lower than the forcing reported by Grini et al. (2002). However, Liao et al. (2004) obtained an even lower estimate of the forcing. Overall, it appears that results from the current study are well within the range of results of other studies.

\subsection{Indirect forcing}

The total indirect effect includes the first indirect effect and the second indirect effect. The forcing that corresponds to the first indirect effect is defined here as the difference of net radiation at the top of atmosphere with and without the contribution of sea salt to cloud effective radius (FIF). The radiation code is thus called twice for different cloud effective radii in one single simulation, to obtain an instantaneous estimate of the forcing.

Figure 11 shows the spatial distributions of FIF for JJA and DJF. The maximum of FIF in the Southern Hemisphere corresponds to the maximum in sea salt burden (Fig. 4). Unlike the sea salt burden, there are no local maximum of the FIF in the Northern Hemisphere for DJF. The relatively weak FIF in the Northern Hemisphere can be attributed to a low sensitivity of the cloud optical properties to changes in the amounts of the sea salt in this area. According to Eq. (14), the cloud droplet number concentration depends only weakly on the sea salt concentration at high sulphate concentrations. 
Table 2. Comparison of the global and annual mean direct radiative forcing due to sea salt. Unit: $\mathrm{W} \mathrm{m}^{-2}$.

\begin{tabular}{llll}
\hline Scale & all-sky/clear sky & Radiative forcing & Reference \\
\hline Global & all-sky & -0.60 & this study \\
& clear & -1.52 & \\
Global & all-sky & -1.1 & Grini et al. (2002) \\
& clear & -2.2 & \\
Global & all-sky & -1.1 & Koch et al. (2006) \\
Global & all-sky & -0.56 & Liao et al. (2004) \\
Global & clear & -0.6 to -2.0 (low wind) & Winter and Chylek (1997) \\
& & -1.5 to -4.0 (high wind) & \\
Global & clear & $-1.51($ low wind) & Haywood et al. (1999) \\
Indian Ocean & clear & -5.03 (high wind) & \\
Indian Ocean & clear & $-1.36 \pm 0.5$ & Podgorny et al. (2000) \\
\end{tabular}

(a)

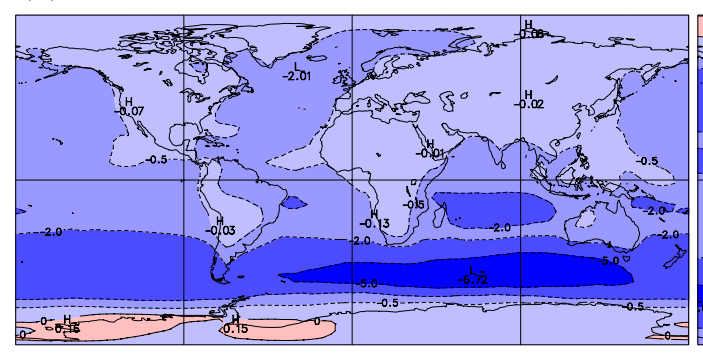

\begin{tabular}{llll|l|ll|l|l|}
-10.0 & -5.0 & -2.0 & -0.5 & 0 & 0.5 & 2.0 & 5.0
\end{tabular} (b)

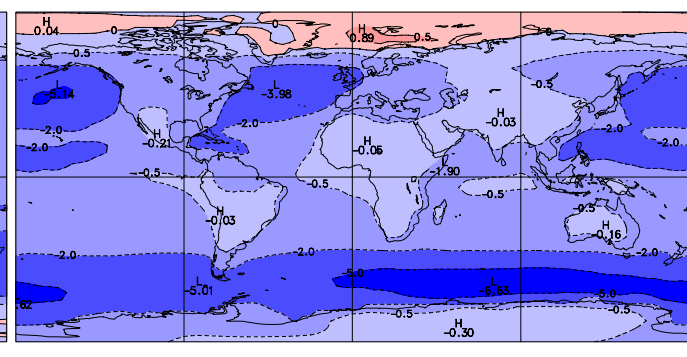

\begin{tabular}{lllll|l|ll|l}
-10.0 & -5.0 & -2.0 & -0.5 & 0 & 0.5 & 2.0 & 5.0
\end{tabular}

Fig. 9. Clear sky instantaneous direct radiative forcing for JJA (a) and DJF (b). Unit: W/m².

(a)
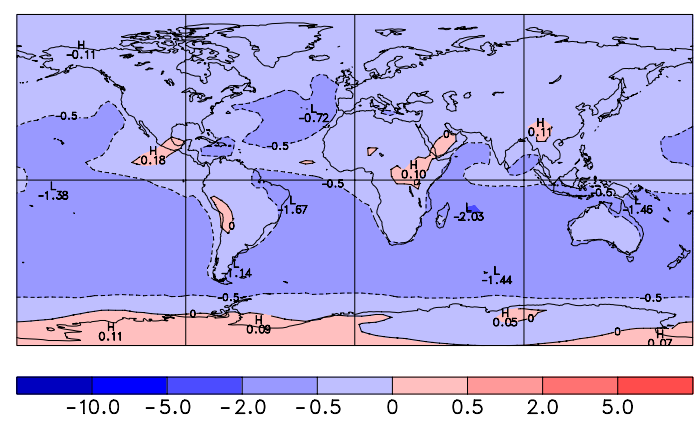

(b)

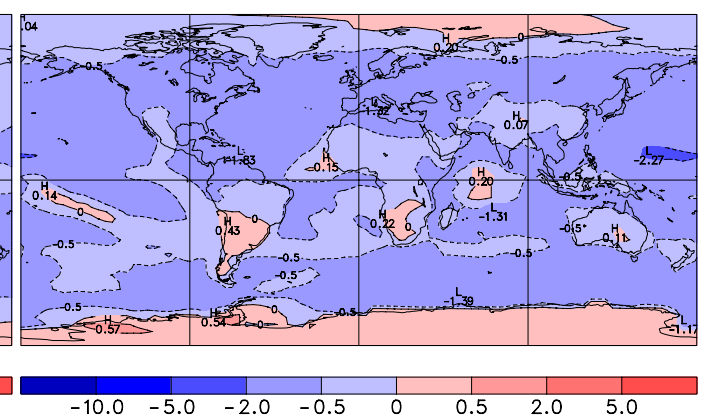

Fig. 10. All sky instantaneous direct radiative forcing for JJA (a) and DJF (b). Unit: $\mathrm{W} / \mathrm{m}^{2}$.

Compared to the Southern Hemisphere, sulphate concentrations are considerably higher in the Northern Hemisphere. Consequently, the contribution of sea salt to the FIF is rather small in the Northern Hemisphere.

The global mean values of the FIF are -1.19 and $-1.27 \mathrm{~W} \mathrm{~m}^{-2}$ for JJA and DJF, respectively. It is noted that the FIF is higher than the direct radiative forcing of sea salt in both seasons. In contrast to the FIF, differences in longwave radiative fluxes at the top of the atmosphere are small.
The calculation of the instantaneous FIF does not account for feedbacks of microphysical and dynamical processes. The change of cloud droplet number and cloud effective radius will affect the efficiency of rain formation via the autoconversion process and atmospheric circulation. In order to investigate the role of feedbacks, the model was modified by removing the sea salt contribution in Eq. (14). Therefore, the modified version of the model does not account for the effects of sea salt on cloud droplet effective radius and 
(a)
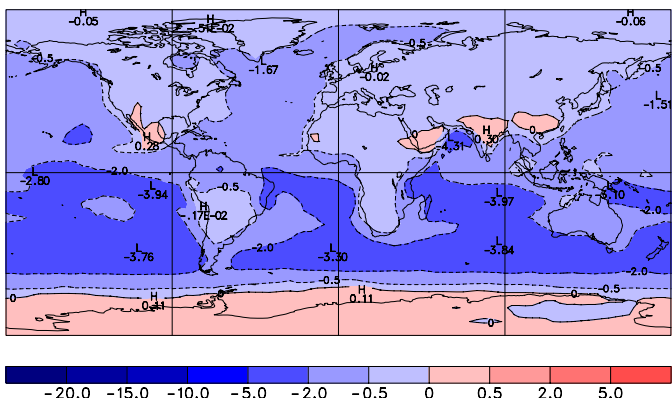

(b)
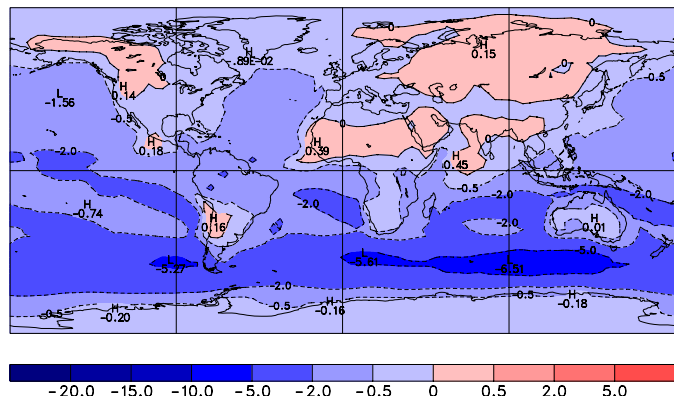

Fig. 11. Instantaneous first indirect radiative forcing for JJA (a) and DJF (b). Unit: $\mathrm{W} / \mathrm{m}^{2}$.

(a)

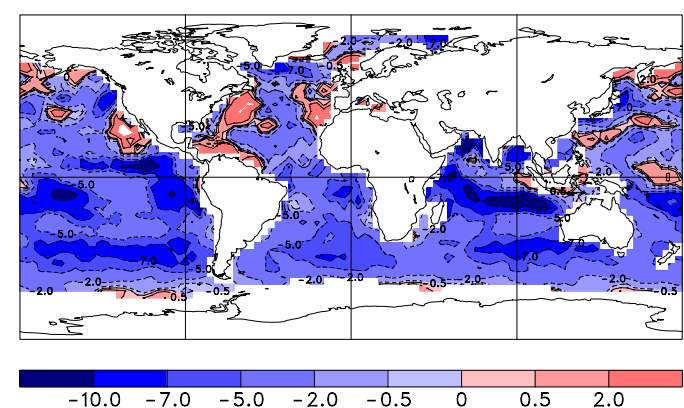

(b)

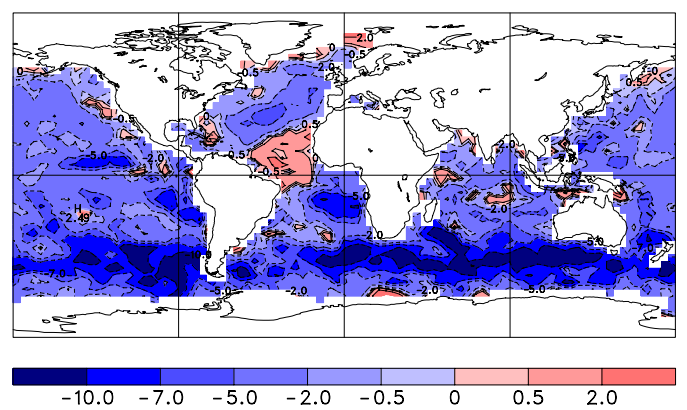

Fig. 12. Indirect sea salt radiative forcing at TOA over ocean for JJA (a) and DJF (b). Unit: W/m².

autoconversion of cloud water to rain. Results of this simulation are compared to the control run with the complete parameterization. The difference of net radiation at the top of atmosphere (TOA) from the two simulations yields the total indirect radiative forcing (TIF), including the first and second indirect effects and contributions from circulation feedbacks.

The results in Fig. 12 show the sea salt TIF over ocean for JJA and DJF. The global mean values are -3.6 and $-3.8 \mathrm{~W} \mathrm{~m}^{-2}$ for JJA and DJF, respectively. The forcings in the Southern ocean are generally around $-5 \mathrm{~W} \mathrm{~m}^{-2}$, similar to the FIF. In contrast to the FIF, some regions in the NH and adjacent to land also produce a positive TIF. If land and sea ice regions are included (Fig. 13), the values of TIF are reduced to -2.7 and $-2.6 \mathrm{~W} \mathrm{~m}^{-2}$ in JJA and DJF, respectively. The distribution of the TIF is anti-correlated to that of the cloud cover change for these simulations (Fig. 14). This indicates that adding the contribution of sea salt to cloud microphysics does not necessarily increase the local cloud cover which would be expected to occur as a consequence of the second indirect effect. For low sea salt concentrations, the cloud cover could may actually decrease due to the changes in circulation which are associated with changes in forcings.

\subsection{Sensitivity of forcings to sea salt aerosol source}

The paramerization of Lewis and Schwartz (2004) (called LS thereafter) relates the sea salt number concentrations to wind speed over ocean, which is different from parameterizations of the sea salt source in terms of surface fluxes (e.g. Monahan et al., 1986; Martensson et al., 2003; Clarke et al., 2006). In order to investigate the sensitivity of sea salt concentrations and its radiative forcing to the sea salt source, the parameterization of Clarke et al. (2006) (called CLK thereafter) was applied in an additional three-year long simulation. A feature of the CLK parameterization is that particle diameters smaller than $0.1 \mu \mathrm{m}$ diameter are also taken into account.

The CLK parameterization provides sea salt fluxes as function of dry particle size and wind speed. For applications in the GCM, the fluxes were integrated over the corresponding particle size sections that are used for the PLA scheme. The resulting fluxes for sea salt aerosol mass and number concentrations are applied in the first model layer above the ocean surface for each individual size section. Three sea salt size sections were used in the simulation for particle diameter ranges $0.01-0.132,0.132-1.2$ and $1.2-8.0 \mu \mathrm{m}$, respectively. Similar to the application of the LS parameterization, sea salt concentrations above the first model layer are predicted 
(a)
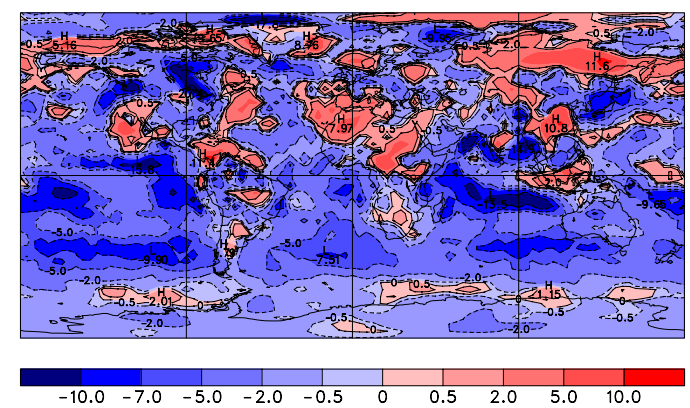

(b)
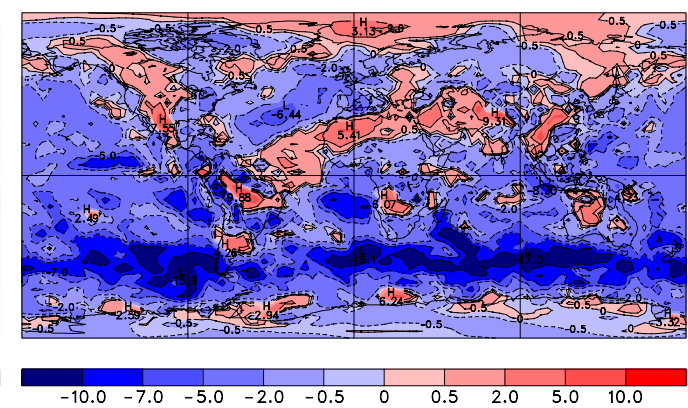

Fig. 13. Indirect sea salt radiative forcing at TOA for JJA (a) and DJF (b). Unit: $\mathrm{W} / \mathrm{m}^{2}$.

(a)

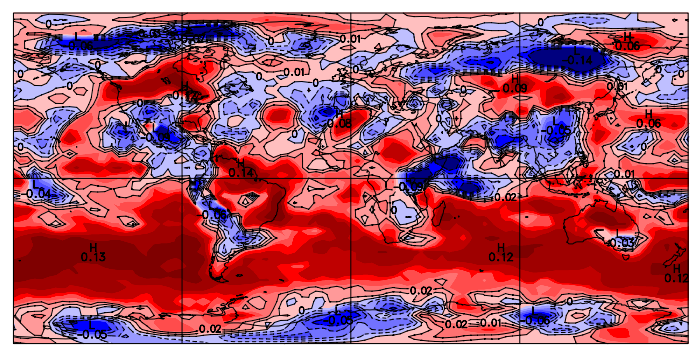

$\begin{array}{cccccccccccccccc}-0.05 & -0.04 & -0.03 & -0.02 & -0.01 & \mid & 0 & 0.01 & 0.02 & 0.03 & 0.04 & 0.05 & 0.07 & 0.10\end{array}$ (b)

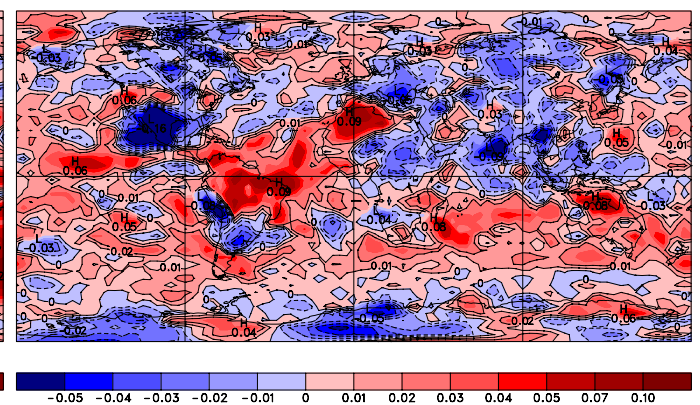

Fig. 14. Total cloud cover change when the effect of sea salt on cloud microphysics are removed from the model for JJA (a) and DJF (b).

based on simulated transport, gravitational settling, and wet removal processes. However, in contrast to simulations based on the LS parameterization, the same processes are now also applied in the first model layer.

Figure 15 shows that the sea salt burden from the simulation with the CLK parameterization is much higher compared to the simulation with the LS parameterization, although the spatial patterns are very similar for both parameterizations. The global annual mean $\left(27.3 \mathrm{mg} \mathrm{m}^{-2}\right)$ in this study is consistent with the study of Pierce and Adams (2006) $\left(25.3 \mathrm{mg} \mathrm{m}^{-2}\right)$. According to Pierce and Adams (2006), the parameterization of Clarke et al. (2006) produces a higher sea salt burden compared to simulations based on the parameterizations by Monahan et al. (1986) and Martensson et al. (2003).

Despite large differences in burdens for simulations with the LS and CLK parameterizations, the clear-sky radiative forcing is very similar for these simulations. The global annual mean direct forcing is -1.40 and $-0.59 \mathrm{~W} \mathrm{~m}^{-2}$ for clear sky and all sky for the CLK parameterization and -1.52 and $-0.60 \mathrm{~W} \mathrm{~m}^{-2}$ for the LS parameterization, respectively. The simulation using the CLK parameterization predicts a comparatively smaller effective radius (Fig. 16). According to results shown in Fig. 1, the extinction coefficient decreases with increasing particle size, i.e. larger particles scatter less efficiently. Owing to compensating effects of reduced scattering efficiency and increased burdens, the simulation based on the CLK parameterization still produces a direct forcing that is very similar to the forcing that was obtained based on the LS parameterization.

Figure 17 shows that the first indirect forcing from the CLK parameterization $\left(-2.1 \mathrm{~W} \mathrm{~m}^{-2}\right)$ is higher than that for the LS parameterization $\left(-1.34 \mathrm{~W} \mathrm{~m}^{-2}\right)$. However, the relative difference in the first indirect forcing is substantially smaller than the relative difference in the burdens between simulations with the LS and CLK parameterizations. The rather small sensitivity of the CDNC to changes in sea salt burdens is caused by a relatively weak dependency of the CDNC on sea salt concentrations for non-zero sulphate concentrations (Eq. 14).

\section{Summary}

A parameterization of size-dependent sea salt aerosols was developed and implemented in the CCCma AGCM for a study on the direct and indirect effects of sea salt aerosols on climate. The treatment of sea salt aerosol is based on the PLA approach. Physical processes such as production, 
(a)

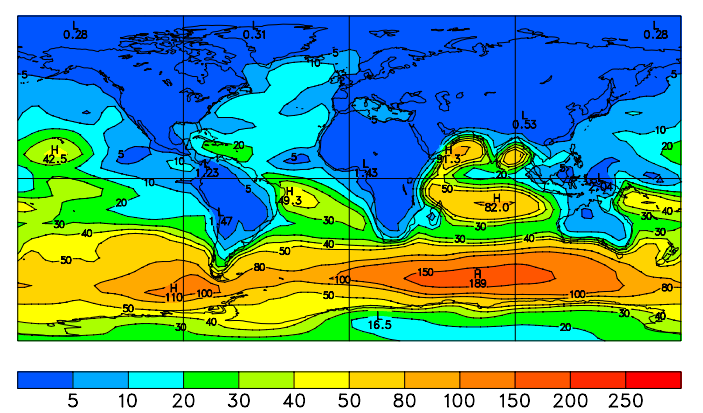

(b)

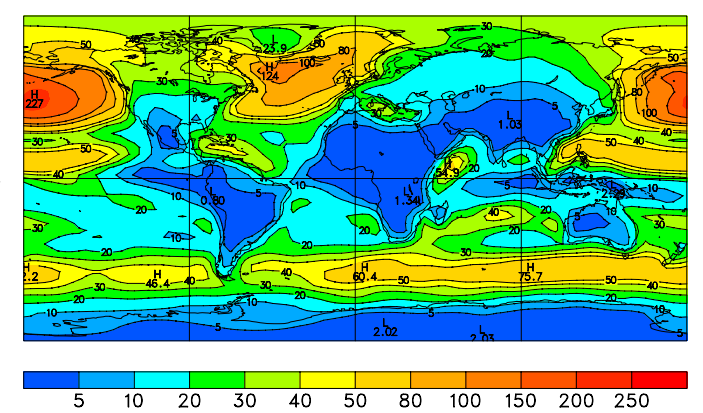

Fig. 15. Simulated sea salt burden (in $\mathrm{mg} / \mathrm{m}^{2}$ ) for JJA (a) and DJF (b) using the Clarke's source function.

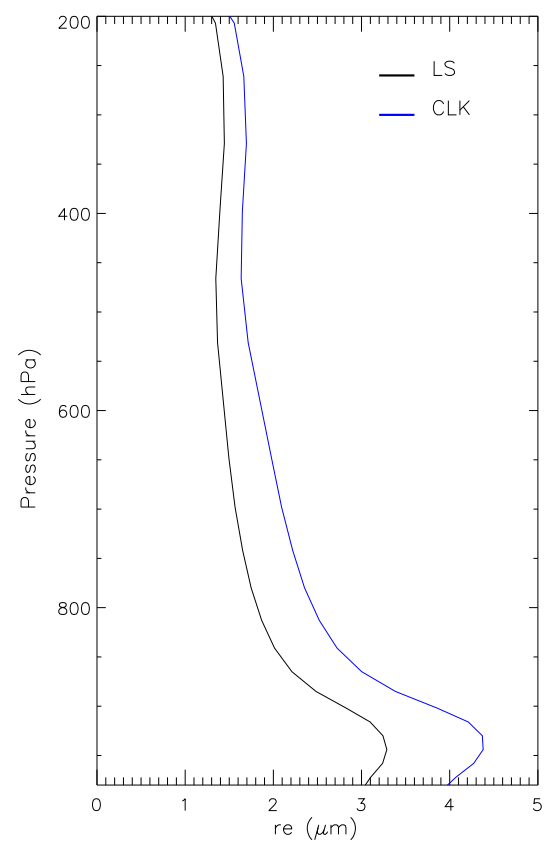

Fig. 16. Vertical profile of the oceanic global mean effective radius.

hygroscopic growth, gravitational settling, and wet deposition are considered in the model.

The simulated sea salt surface concentrations over the ocean are generally consistent with surface observations although the model tends to produce too low sea salt burdens for tropical regions. The good consistency between the model and AERONET shows that the model is able to reproduce the basic features of the sea salt size distribution.

The distribution and seasonal variation of the direct forcing is similar to the seasonal variation of sea salt concentrations. The annual mean instantaneous radiative forcing from the first indirect effect of sea salt is estimated as $-1.34 \mathrm{~W} \mathrm{~m}^{-2}$, with little seasonal variation. Much stronger forcings occur locally in the simulation, especially in regions with high wind speeds in the Southern Hemisphere.
In order to investigate the total indirect radiative forcing of sea salt, the contributions of sea salt to cloud optical and microphysical processes in the model were removed and results compared to the results from the complete model. According to this approach, the total indirect radiative forcing from sea salt resembles the forcing that is associated with the first indirect effect of sea salt in the Southern Hemisphere. However, the total indirect forcing is over 100\% higher than the forcing from the first indirect effect in the global mean $\left(-2.9 \mathrm{~W} \mathrm{~m}^{-2}\right)$. There are also regions (mostly over land) which are associated with a positive total radiative forcing. This can be attributed to changes in the distribution of clouds owing to changes in the radiative forcing and circulation.

The sum of global mean direct and first indirect radiative forcings for sea salt are similar to the corresponding forcing that is associated with sulphate aerosol. Consequently, changes in climate may potentially lead to important radiative feedbacks from sea salt aerosol via changes in the strengths of sources and sinks for sea salt. Further studies based on coupled atmosphere/oceans GCMs should be performed for investigations of these feedbacks. Particular emphasis should be on the Southern Hemisphere for which effects of sea salt on temperatures and circulation may be considerable.

It is acknowledged that implications of aerosol-cloud interactions for climate are not yet well understood by the scientific community. Although basic aspects of the direct and first indirect effects of sea salt on climate are useful results from model that are based on empirical relationships between aerosol and cloud droplet concentrations, considerable uncertainties are associated with forcing estimates. A parameterization with a more rigorous treatment of aerosol-cloud interactions is currently under development at CCCma (von Salzen et al., 2007). We will examine the uncertaities of the empirical relationship for activation using the new aproach in the future. 
(a)

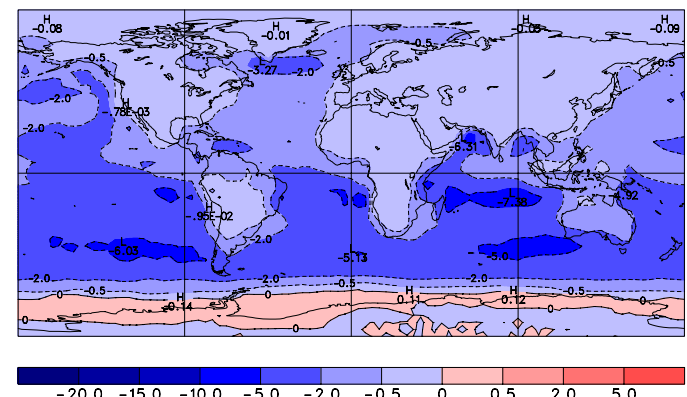

(b)

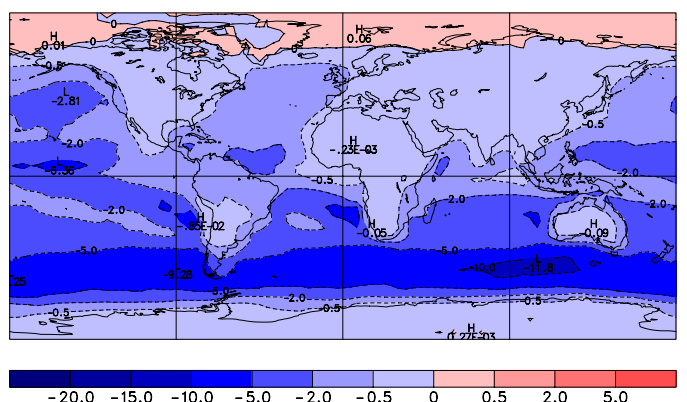

Fig. 17. Instantaneous first indirect radiative forcing for JJA (a) and DJF (b) using the Clarke's source function. Unit: W/ $\mathrm{m}^{2}$.

Acknowledgements. We thank two internal reviewers at CCCma, J. Scinocca and B. Merryfield, for their helpful comments. Funding for this study has been provided by NSERC, the Canadian Foundation for Climate and Atmospheric Sciences (CFCAS) network "Cloud-Aerosol Feedbacks and Climate (CAFC)", and Environment Canada.

Edited by: V.-M. Kerminen

\section{References}

Abdul-Razzak, H. and Ghan, S. J.: A parameterization of aerosol activation 2. multiple aerosol type, J. Geophys. Res., 105, 68376844, 2000.

Abdul-Razzak, H. and Ghan, S. J.: A parameterization of aerosol activation 3. sectional representation, J. Geophys. Res., 107(D3), 4026, doi:10.1029/2001JD000483, 2002.

Abdul-Razzak, H., Ghan, S. J., and Ricera-Carpio, C.: A parameterization of aerosol activation 1. single aerosol type, J. Geophys. Res., 103, 6123-6131, 1998.

Ackerman, A. S., Kirkpatrick, M. P., Stevens, D. E., and Toon, O. B.: The impact of humidity above stratiform clouds on indirect aerosol climate forcing, Nature, 432, 1014-1017, 2004.

Ackermann, I. J., Hass, H., Memmesheimer, M., Ebel, A., Binkowski, F. S., and Shankar, U.: Modal aerosol dynamics model for Europe: Development and first applications, Atmos. Environ., 32, 2981-2999, 1998.

Albrecht, B. A., Aerosols, clouds microphysical, and fractional cloudiness, Science, 245, 1227-1230, 1989.

Anguelova, M. D. and Webster, F.: Whitecap coverage from satellite measurements: A first step toward modeling the variability of oceanic whitecaps, J. Geophys. Res., 111, C03017, doi: 10.1029/2005JC003158, 2006.

Berge, E.: Coupling of wet scavenging of sulphur to clouds in a numerical weather prediction model, Tellus, 45(B), 1-22, 1993.

Blanchard, D. C. and Woodcock, A. H.: The production, concentration and vertical distribution of the sea-salt aerosol, Tech. Rep., Annals of the New York Academy of Sciences, 338 pp., 1980.

Borys, R. D., Lowenthal, D. H., Wetel, M. A., Rosa, F., Gonzalez, A., and Harris, J.: Chemical and microphysical properties of marine stratus clouds in the north atlantic, Atmos. Envion., 34, 22 073-22 085, 1998.
Boucher, O. and Lohmann, U.: The sulfate-CCN-cloud albedo effect: a sensitivity study with two general circulation models, Tellus, 47B, 281-300, 1995.

Clarke, A. D., Owens, S. R., and Zhou, J.: An ultrafine sea-salt flux from breaking waves: Implications for $\mathrm{CCN}$ in the remote marine atmosphere, J. Geophys. Res., 111, D06202, doi:10.1029/ 2005JD006565, 2006.

Covert, D. S., Kaputin, V. N., Bates, T. S., and Quinn, P. K.: Physical properties of marine boundary layer particles of the midPacific in relation to sources and meteorological tranport, J. Geophys. Res., 101, 6919-6930, 1996.

Croft, B., Lohmann, U., and von Salzen, K.: Black carbon aging in the canadian centre for climate modelling and analysis general circulation model, Atmos. Chem. Phys., 5, 1383-1419, 2005, http://www.atmos-chem-phys.net/5/1383/2005/.

Feingold, G., Cotton, W. R., Kreidenweis, S. M., and Davis, J. T.: The impact of giant cloud condensation nuclei on drizzle formation in startocumulus: implications for cloud radiative properties, J. Atmos. Sci., 36, 4100-4117, 1999.

Gelbard, F.: Modeling multicomponent aerosol particle growth by vapor condensation, Aerosol Sci. Technol., 12, 399-412, 1990.

Gelbard, F. and Seinfeld, J. H.: Simulation of multicomponent aerosol dynamics, J. Colloid Interface Sci., 78, 485-501, 1980.

Ghan, S. J., Leung, L. R., Easter, R. C., and Abdul-Razzak, H.: Prediction of cloud droplet number in a general circulation model, J. Geophys. Res., 102, 21 777-21 794, 1997.

Gong, S.-L., Barrie, L. A., and Blanchet, J. P.: Modeling sea salt aerosols in the atmosphere 1. Model development, J. Geophys. Res., 102, 3805-3818, 1997.

Gong, S.-L., Barrie, L. A., Blanchet, J. P., von Salzen, K., Lohnmann, U., Lesins, G., Spacek, L., Zhang, L.-M., Girard, E., Lin, H., Leaitch, R., Leighton, H., Chylek, P., and Huang, P.: Canadian aerosol mudule: A size-segregated simulation of atmospheric aerosol processes for climate and air quality models 1. module development, J. Geophys. Res., 108(D1), 4007, doi: 10.1029/2001JD002002, 2003.

Grini, A., Myhre, G., Sundet, J. K., and Isaksen, I. S. A.: Modeling the annual cycle of sea salt in the global 3D model Oslo CTM2: Concentrations, fluxes, and radiative impact, J. Climate, 15, 1717-1730, 2002.

Haywood, J., Ramaswamy, V., and Soden, B.: Tropospheric aerosol climate forcing in clear sky satellite observation over the oceans, Science, 283, 1299-1303, 1999. 
Holben, B. N.: AERONET: A federated instrument network and data archive for aerosol characterization, Remote Sens. Environ., 66, 1-16, 1998.

Jacobson, M. Z.: Development and application of a new air pollution modeling system - II. aerosol module structure and design, Atmos. Environ., 31, 113-144, 1997.

Jones, A. R. and Slingo, D. L.: A climate model study of indirect radiative forcing by anthropogenic sulphate aerosols, Nature, 370, 450-453, 1994.

Khairoutdinov, M. and Kogan, Y.: A new cloud physics parameterization in a large-eddy simulation model of marine stratocumulus, Mon. Weather Rev., 128, 229-243, 2000.

Koch, D., Schmidt, G. A., and Field, C. V.: Sulfur, sea salt, and radionuclide aerosols in GISS ModelE, J. Geophys. Res., 111, D06206, doi:10.1029/2004JD005550, 2006.

Koepke, P., Schult, M., and Shettle, E.: Global aerosol data set. Max Planck Institute for Meteorology, Tech. Rep. 243, Hamburg, Germany, 1997.

Leaitch, W. R., Banic, C. M., Issac, G. A., and Couture, M. D.: Physical and chemical observations in marine stratus during the 1993 North Atlantic Regional Experiments: Factors controlling cloud droplet number concentrations, J. Geophys. Res., 101, 29 123-29 135, 1996.

Lewis, E. and Schwartz, S. E.: Sea salt aerosol production: Mechanisms, Methods, Measurements, and Models, Whiley, New York, 2004.

Liao, H., Seinfeld, J. H., Adams, P. J., and Mickley, L. J.: Global radiative forcing of coupled tropospheric ozone and aerosols in a unified general circulation model, J. Geophys. Res., 198, D16207, doi:10.1029/2003JD004456, 2004.

Loeb, N. G. and Manalo-Smith, N.: Top of atmospheric direct radiative effect of aerosols over global ocean from merged CERES and MODIS observations, J. Climate, 18, 3506-3526, 2005.

Lohmann, U. and Roeckner, E.: Design and performance of a new cloud microphysics scheme developed for the ECHAM general circulation model, Clim. Dynam., 12, 557-572, 1996.

Lohmann, U., and von Salzen, K., and McFarkan, N., and Leighton, H. G., and Feichter, J.: Tropospheric sulphur cycle in the Canadian Gerenal Circulation Model, J. Geophys. Res., 104, $26833-$ $26858,1999$.

Lowenthal, D. H., Borys, R. D., Choularton, T. W., Bower, K. N., Flynn, M. J., and Gallagher, M. W.: Parameterization of the cloud droplet-sulfate relationship, Atmos. Envion., 38, 287-292, 2004.

Lurmann, F. W., Wexler, A. S., Pandis, S. N., Musarra, S., Kumar, N., and Seinfeld, J. H.: Modeling urban and regional aerosols, application to California's South Coast Air Basin, Atmos. Emviron, 31, 2695-2715, 1997.

Ma, X.-Y. and von Salzen, K.: Dynamics of the sulphate aerosol size distribution on a global scale, J. Geophys. Res., 111, D08206, doi:10.1029/2005JD006620, 2006.

Mahowald, N. M., Lamarque, J. F., Tie, X., and Wolff, E.: Seasalt aerosol response to climate change: Last Glacial Maximum, preindustrial, and doubled carbon dioxide climates, J. Geophys. Res., 111, D05303, doi:10.1029/2005JD006459, 2006.

Märtensson, E. M., Nilsson, E. D., de Leeuw, G., Cohen, L. H., and Hansson, H. C.: Laboratory simulations and parameterizations of the promary marine aerosol productions, J. Geophys. Res., 108(D9), 4297, doi:10.1029/2002JD002263, 2003.
McGraw, R.: Description of aerosol dynamics by the quadrature method of moments, Aerosol Sci. Technol., 27, 255-265, 1997.

Meng, Z. Y., Dabdub, D., and Seinfeld, J. H.: Size-resolved and chemically resolved model of atmospheric aerosol dynamics, J. Geophys. Res., 103, 3419-3435, 1998.

Monahan, E. C., Spiel, D. E., and Davidson, K. L.: A model of marine aerosol generation via whitecaps and wave disruption, in oceanic whitecaps, edited by: Monahan, E. C. and Mac Niocaill, G., Tech. Rep., D. Reidel, Norwell, Mass, 1986.

Nenes, A. and Seinfeld, J. H.: Parameterization of cloud droplet formation in global climate models, J. Geophys. Res., 108(D14), 4415, doi:10.1029/2002JD002911, 2003.

O'Dowd, C. D., Lowe, J. A., and Smith, M. H.:a), The relative importance of non-sea-salt sulphate and sea salt aerosols to the marine cloud condensation nuclei population: An improved multicomponent aerosol-cloud droplet parameterization, Q. J. Roy. Meteor. Soc., 125 (556), 1295-1313, 1999.

O’Dowd, C. D., Lowe, J. A., and Smith, M. H.:b), Coupling sea-salt and sulphate interactions and its impact on cloud droplet concentration predictions, J. Geophys. Res., 26, 1311-1314, 1999.

Penner, J. E., and Quaas, J., and Storelvmo, T., and Takemura, T., and Huo, H., and Kirkevag, A., and Kristjansson, J. E., and Seland, Q.: Model intercomparison of indirect aerosl effects, Atmos. Chem. Phys., 6, 1579-1617, 2006, http://www.atmos-chem-phys.net/6/1579/2006/.

Pierce, J. R. and Adams, P. J.: Global evalustion of CCN formation by direct emission of sea salt and growth of ultrafine sea salt, J. Geophys. Res., 111, D06203, doi:10.1029/2005JD006186, 2006.

Pilinis, C., Capaldo, K. P., Nenes, A., and Pandis, S. N.: MADMA new multicomponent aerosol dynamics model, Aerosol Sci. Technol., 32, 482-502, 2000.

Podgorny, I. A., Conant, W. C., Ramanathan, V., and Satheesh, S. K.: Aerosol modulation of the surface and atmospheric solar heating over the tropical Indian Ocean, Tellus, 52B, 947-958, 2000.

Pryor, S. C. and Sorensen, L. L.: Nitric acid-sea salt reactions: Implications for nitrogen deposition to water surfaces, J. Appl. Meteor., 39, 725-731, 2000.

Quinn, P. K., Kapustin, V. N., Bates, T. S., and Covert, D. S.: Chemical and optical properties of marine boundary layer aerosol particles of the mid-Pacific in relation to sources and meteorological tranport, J. Geophys. Res., 101, 6931-6951, 1996.

Quinn, P. K., Coffman, D. J., Kapustin, V. N., Bates, T. S., and Covert, D. S.: Aerosol optical properties of marine boundary layer during ACE 1 and underlaying chemical and physical aerosol properties, J. Geophys. Res., 103, 16547-16563, 1998.

Quinn, P. K., Coffman, D. J., Kaputin, V. N., Bates, T. S., and Covert, D. S.: Surface submicron aerosol chemical composition: What fraction is not sulfate, J. Geophys. Res., 105, 6785-6805, 1999.

Quinn, P. K., Coffman, D. J., Kaputin, V. N., Bates, T. S., and Covert, D. S.: A comparison of aerosol chemical and optical properties from the 1 st and 2 nd aerosol characterization experiments, Tellus B, 52(2), 239-257, 2000.

Reader, C. M. and McFarlane, N.: Sea-salt aerosol distribution during the Last Glacial Maximumand its implications for mineral dust, J. Geophys. Res., 108(D8), 4253, doi:10.1029/ 2002JD002063, 2003.

Russell, L. M. and Seinfeld, J. H.: Size-and composition-resolved 
external mixed aerosols model, Aerosol Sci. Technol., 28, 403416, 1998.

Satheesh, S. K. and Lubin, D.: Short wave versus long wave radiative forcing due to aerosol over indian ocean: Role of seasurface winds, Geophys. Res. Lett., 30(13), 1695, doi:10.1029/ 2003GL017499, 2003.

Seinfeld, J. H. and Pandis, S. N.: Atmospheric chemistry and physics: From air pollution to climate change, Whiley, New York, 1998.

Smith, M. H., Park, P. M., and Consterdine, I. E.: Marine aerosol concentration and estimated fluxes over sea, Q. J. Roy. Meteor. Soc., 119, 809-824, 1993.

Stratman, F., Kiselev, A., Wurzler, S., Wendisch, M., Heintzenberg, M., Charlson, J., Diehl, J., Wex, K., and Schmidt, S.: Laboratory studies and numerical simulations of cloud droplet formation under realistic supersaturation conditions, J. Atmos. Ocean. Technol., 21, 876-887, 2004.

Takemura, T., Okamoto, H., Maruyama, Y., Numagati, A., Higurashi, A., and Nakajima, T.: Global three-dimensional simulation of aerosol optical thickness distribution of various origins, J. Geophys. Res., 105, 17 853-17 873, 2000.

Tang, I. N., Tridico, A. C., and Fung, K. H.: Thermodynamic and optical properties of sea salt aerosols., J. Geophys. Res., 102, 23 269-23 277, 1997.

Tegen, I., Hollrig, P., Chin, M., Fung, I., Jacob, D., and Penner, J.: Contribution of different aerosol species to the global aerosol extinction optical thickness: Estimates from model results, J. Geophys. Res., 102, 23 895-23 915, 1997.

Textor, C., Schulz, M., Kinne, S., Balkanski, Y., Bauer, S., Berntsen, T., Berglen, T., Boucher, O., Chin, M., Dentener, F., and Diehl, T.: Analysis and quantification of the diversities of aerosol life cycles within AeroCom, Atmos. Chem. Phys., 6, 1777-1813, 2006, http://www.atmos-chem-phys.net/6/1777/2006/.

Twomey, S.: Pollution and the planery albedo, Atmos. Environ., 8, 1251-1256, 1974.

von Salzen, K.: Piecewise log-normal approximation of size distributions for aerosol modelling, Atmos. Chem. Phys., 6, 13511372, 2006,

http://www.atmos-chem-phys.net/6/1351/2006/. von Salzen, K. and Schlünzen, K. H.: A prognostic physicochemical model of secondary and marine inorganic multicomponent aerosols, I: Model description, Atmos. Environ., 33, 567576, 1999.

von Salzen, K., McFarlane, N. A., and Lazare, M.: The role of shallow convection in the water and energy cycles of the atmosphere, Clim. Dynam., 25, 671-699, doi:10.1007/s00382-005-0051-2, 2005.

von Salzen, K., Ma, X., and Li, J.: A new approach for representation of aerosol/cloud interactions in climate models, Book of abstracts, A-Train-Lille 07 - Symposium, 22-25 October, Lille, France, p. 126, 2007.

Warren, D. R. and Seindeld, J. H.: Simulation of aaerosol size distribution evolution in systems with simulations nucleation, condensation, and coagulation, Aerosol Sci. Technol., 4, 31-43, 1985.

Whitby, E. R. and McMury, P. H.: Modal aerosol dynamics modeling, Aerosol Sci. Technol., 27, 673-688, 1997.

Whitby, K. T.: Determination of aerosol growth rates in the atmosphere using lumped aerosol dynamics, J. Aerosol Sci., 12, 174$178,1981$.

Wilson, J., Cuverlier, C., and Raes, F.: A modeling study of global mixed aerosol fields, J. Geophys. Res., 106, 34 081-34 108, 2001.

Winter, B. and Chylek, P.: Contribution of sea salt aerosol to the planetary clear-sky albedo, Tellus B, 49(1), 72-79, 1997.

Wright, D. L., Kasibhatla, P. S., McGraw, R., and Schwartz, S. E.: Description and evaluation of a six-moment aerosol microphysical module for use in atmospheric chemistry transport models, J. Geophys. Res., 106, 20 275-20 291, 2001.

Yu, S., Kasibhatla, P. S., Wright, D. L., Schwartz, S. E., and McGraw, R.: Moment-based simulation of microphysical properties of sulfate aerosols in the eastern united states: Modal description, evaluation, and regional analysis, J. Geophys. Res., 108(D12), 4353, doi:10.1029/2002JD002890, 2003. 